\title{
Social preferences for adaptation measures to conserve Australian birds threatened by climate change
}

\author{
Stephen T. Garnett, Kerstin K. Zander, Shannon Hagerman \\ Terre A. Satterfield and Jürgen Meyerhoff
}

\begin{abstract}
Debate about climate change adaptation for biodiversity, and the ethics and consequences of assisted colonization in particular, has polarized professional opinion but the views of the wider community are unknown. We tested four hypotheses about the acceptability of adaptation strategies among a sample of the Australian general public using a combination of direct questions and a choice experiment. We found that (1) among the $80 \%$ who wanted extinction avoided, increased in situ management of wild populations was preferred to captive breeding or assisted colonization, (2) preferences for adaptation strategies were not explained by gender, income, education or knowledge about birds, (3) genetically distinctive taxa were not actively preferred, (4) $>60 \%$ of respondents were content for conservation managers to make decisions about strategies rather than local communities or the general public. The results provide Australian policy makers with a mandate to bolster efforts to retain existing populations but suggest that assisted colonization and captive breeding could be accepted if essential.
\end{abstract}

Keywords Assisted colonization, biodiversity, captive breeding, choice experiment, climate change, threatened species

The supplementary material for this article can be found at https://doi.org/10.1017/So030605316001058

\section{Introduction}

$\mathrm{M}$ any potential approaches to helping biodiversity adapt to climate change are controversial (Tam \&

STEPHEN T. GARNETT Research Institute for the Environment and Livelihoods, Charles Darwin University, Darwin, Australia

KeRstin K. ZANDER (Corresponding author) Northern Institute, Charles Darwin University, Darwin, Australia. E-mail kerstin.zander@cdu.edu.au

Shannon Hagerman Department of Forest Resources Management, University of British Columbia, Vancouver, Canada

Terre A. SATterfield Institute for Resources, Environment and Sustainability, University of British Columbia, Prince George, Canada

JÜRgen Meyerhoff Institute of Landscape Architecture and Environmental Planning, Technische Univerität Berlin, Germany

Received 19 May 2016. Revision requested 2 August 2016.

Accepted 5 September 2016. First published online 10 January 2017.
McDaniels, 2013), with solutions as much values-based as technical (Hewitt et al., 2011) and with pros and cons evident in all options. Assisted colonization (also called assisted migration; Hewitt et al., 2011), in which climate-challenged taxa are moved to places where the climate is predicted to be more suitable, may also provide opportunities for invasive species (Ricciardi \& Simberloff, 2009). Adaptive introgression, where new genes that could aid adaptation are introduced to climate-affected populations (Hamilton \& Miller, 2016), can compromise species integrity (Gómez et al., 2015). Captive breeding will inevitably cause loss of genetic variability (Araki et al., 2007) even if current capacity constraints (Alroy, 2015) can be overcome. Less intrusive approaches, such as intensified in-situ management of sensitive species, are potentially only short-term investments given the inevitability of climate change (West et al., 2009). Landscape corridors can aid the spread of invasive species (Resasco et al., 2014).

This uncertainty about outcomes means policy makers have little clear direction regarding how best to allocate adaptation investment, or whether to invest at all. This is because it is unclear which, if any, potential adaptation action has the strongest social licence to proceed (Klenk \& Larson, 2013). As is evident from the broader climate change debate, technical disagreements potentially create space for opponents of potential adaptation actions to delay changes by increasing political risk (Ceccarelli, 2011). Thus, actions lacking a social licence are unlikely to receive either authorization from the State or the public funding that will in most cases be required to put them into effect (Burbidge et al., 2011). Social responses to climate change adaptation are both culturally contingent and malleable (Adger et al., 2013); nonetheless, establishing the strength of public opinion before any actions are decided can both inform policy and enhance political confidence in the face of potential opposition.

Some studies have gauged the opinion of conservation scientists on climate change adaptation (Hagerman et al., 2010; Hagerman \& Satterfield, 2014; Hancock \& Gallagher, 2014). Scientific knowledge is certainly essential to understanding the technical feasibility of management. However, in a democracy, the opinions of scientists about public policy have no more legitimacy than those of lay members of the public. There are many examples of environmental legislation that protects even obscure species, 
about which the public has little knowledge, including some with substantial economic, social and political consequences. Thus, policy makers need to understand public opinion even where there is likely to be little understanding of the positions held by conservation scientists or of the technical matters relating to those positions.

Our main aim is to ascertain the current level of acceptance by the Australian public of proposed conservation actions that would help birds adapt to climate change. These are based on realistic scenarios and associated actions that emerged from an analysis of the effects of climate on all Australian birds, which showed that for c. 100 bird taxa the climate where they currently live will be quite different in 50 years (Garnett et al., 2014). The proposed conservation management actions were increased in situ conservation, assisted colonization and the establishment of captive populations (e.g. in zoos). Experts favour greater investment in reducing threats in situ over assisted colonization (Hancock \& Gallagher, 2014), but no survey had been conducted among the general public in Australia or elsewhere to investigate whether they knew or cared about proposed actions at this stage in the debate.

Also, because choices about which birds to conserve are likely to be compounded by the attractiveness of the taxa concerned, we tried to choose birds with a relatively low public profile. We also chose a mixture of species and subspecies with various levels of taxonomic distinctiveness (i.e. the level of genetic relatedness to other bird taxa). Although taxonomic distinctiveness was first suggested as the basis for prioritizing the conservation of threatened birds $>20$ years ago (Faith, 1992, 2002; Garnett, 1992; Weitzman, 1998) and has been used to choose between species for investment in New Zealand (Joseph et al., 2009), no distinction is made in legislation designed to conserve species in any nation examined (Garnett \& Christidis, 2007). Also, there is no information on whether taxonomic distinctiveness is understood or used by the public in choosing among taxa to conserve.

We therefore endeavoured to understand the current preferences of the Australian public in three states where actions that could help species adapt to climate change may occur, with the objective of informing policy makers about which could be socially acceptable.

\section{Methods}

\section{Case study birds and survey instrument}

To test preferences for management actions we conducted a questionnaire survey of 1,119 members of the Australian public living within the ranges of four bird taxa. Previous modelling (Garnett et al., 2014) has suggested that much of their habitat will be climatically unsuitable for these birds by 2085 (Fig. 1).
The first section of the questionnaire described the four case study birds and potential adaptation strategies for securing their future (Supplementary Material 1). The bird taxa were the rufous scrub-bird Atrichornis rufescens, one of only two members of an ancient Australian passerine bird family, the Atrichornithidae; the scrubtit Acanthornis magna, one of two endemic monotypic Tasmanian species but a member of a widespread family, the Acanthizidae; and two subspecies of another member of the Acanthizidae, the relatively common and widespread brown thornbill Acanthiza pusilla, one from mainland Australia (A. pusilla pusilla) and one from Tasmania (A. pusilla tasmanicus). By 2085 areas in Tasmania will potentially have suitable climatic characteristics for the scrub-bird and mainland subspecies of thornbill, similar to where they currently occur, and to which they could be moved. The scrub-bird has no close relatives in Tasmania. The mainland subspecies of brown thornbill would probably interbreed with individuals of the Tasmanian subspecies, meaning neither population would be the pure form. The scrubtit and the Tasmanian thornbill subspecies have no prospective climate space in Australia but adaptation options offered for all four taxa included both intensive management within their current range to help birds cope with climate change, and keeping populations in zoos indefinitely. The status quo was to do nothing, with the most likely consequence being eventual extinction.

The background information was written in a way that would avoid bias. For example, because we aimed to establish general principles for conservation preferences, rather than specific advice on the case study birds, we described the four taxa in bland descriptive language to reduce the chances of charisma bias (Brambilla et al., 2013), providing enough information for respondents to understand the likely consequences of climate change but with no attempt to emphasize their conservation merit. Thus we noted only that two of the bird taxa were subspecies of the same species, even though the scub-bird and scrubtit are more distinct than the two thornbill subspecies. We felt that such differences could influence the preferences of respondents with existing knowledge but that we could not have provided that knowledge as part of the questionnaire without implying higher levels of distinctiveness had greater value.

To understand which, if any, management actions are preferred as a means of assisting species to cope with climate change we reviewed those recommended by Garnett et al. (2014) and chose the following: (1) increased in situ support for wild populations in their current locations ('in situ' described as helping a species stay where it is), (2) assisted colonization ('assisted colonization' described as moving a taxon to Tasmania), and (3) the establishment of captive populations ('captivity' described as keeping in a zoo). Respondents were asked to choose their most preferred management option out of three options in a choice set 


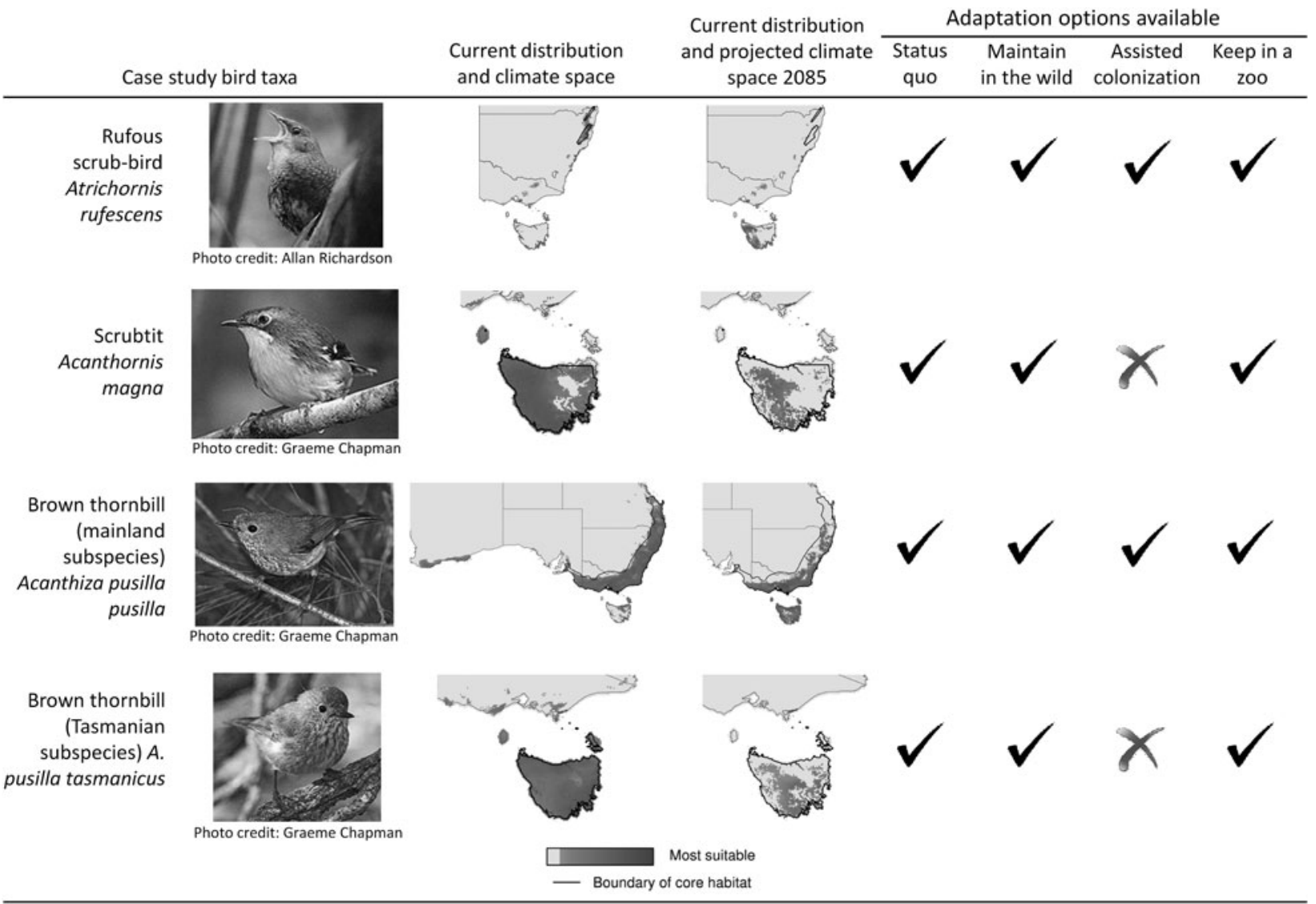

Fig. 1 Characteristics of four Australian bird taxa likely to be affected deleteriously by climate change, their current distributions in comparison to modelled habitat suitability in 2014 and 2085, and the options available for climate change adaptation. The projected climate space in 2085 comprises areas with a climate resembling that currently occupied by the taxon (Garnett et al., 2014).

(see below). In this way they considered the importance to them of both the bird type they wanted to see conserved and the action they thought should be pursued. The acceptability of other adaptation options, such as the creation of habitat corridors, could not be tested because Tasmania is separated from the mainland by a substantial water body. This also prevented testing acceptability of natural climate refugees (Lundhede et al., 2014), as none of the case study taxa naturally cross marine barriers. Accounts of the alternative adaptation actions were described in plain language that tried to avoid potentially value-laden words or phrases, again to avoid bias as much as possible. We assumed all approaches were technically feasible and that the costs would be met from government tax revenue, which is usually the case for conservation in Australia, rather than from direct personal donations.

\section{Design of the choice experiment}

In an online survey, respondents were presented with a choice experiment, which systematically manipulates a set of attributes within each choice; such choice or preference elicitations are widely used to reveal preferences through requested trade-offs that may not be evident from more direct questions (Hensher et al., 2015). This means that, on the basis of a combination of prior knowledge and the information provided in the questionnaire, respondents choose between options that involve trade-offs among a mix of desirable and undesirable outcomes. The strength of feelings about the different options is then revealed through analysis of responses to a series of choice sets, in each of which the costs and outcomes of attributes are varied. In this case respondents were asked to choose the conservation option in which they think the Australian Government should invest. Each option involved a set of hypothetical conservation actions, one of which was the status quo, in which birds would be left to cope with climate change without external assistance. The remaining two offered alternative trade-offs between birds and management actions (Fig. 2).

We used a Bayesian approach for the experimental design underlying the choice experiment. Each bird taxon represented an attribute that could take two or three levels in addition to the status quo option 'Leave it to cope'. The levels were 'Help it stay where it is' and 'Keep it in a zoo' for all taxa. The management action 'Move it to Tasmania' was 
In this set of three options there are two (Management options A and B) for which the Government would pay to manage birds threatened by climate change, and one in which no money would be spent (No special management).

If only these three options were available, which one would you prefer? (A reminder about which bird is which is at the bottom of the page.)

\begin{tabular}{|c|c|c|c|}
\hline & Management option A & Management option B & No special management \\
\hline Rufous scrub-bird & Leave it to cope & Move it to Tasmania & Leave it to cope \\
\hline Scrubtit & Keep it in a zoo & Keep it in a zoo & Leave it to cope \\
\hline $\begin{array}{l}\text { Brown thornbill-mainland } \\
\text { form }\end{array}$ & Keep it in a zoo & Leave it to cope & Leave it to cope \\
\hline $\begin{array}{l}\text { Brown thornbill-Tasmanian } \\
\text { form }\end{array}$ & Help it stay where it is & Keep it in a zoo & Leave it to cope \\
\hline
\end{tabular}

Reminder:

Rufous scrub-bird: Occurs in mountain forests in south-east Queensland and north-east New South Wales but in the future the best climate for it may be in Tasmania.

Scrubtit: Occurs only in the wet forests of Tasmania but the climate there may change completely.

Brown thornbill-mainland form: Occurs in the forests and woodlands of south-east Australia. Could be moved to Tasmania to follow suitable climate but would mix with the form of brown thornbill already there.

Brown thornbill-Tasmanian form: Occurs in the forests and woodlands of Tasmania. The climate there may become unsuitable but the Tasmanian form could be replaced by the mainland form.

FIG. 2 Example of a choice set and accompanying text as presented to respondents in an online survey.

possible for the two mainland taxa. To allocate attribute levels to alternative choice sets a Bayesian d-efficient design was optimized for a conditional logit model (Rose \& Bliemer, 2014) in a two-step procedure. Firstly, we created a design using uniform priors for which the interval boundaries were taken from previous studies. This design was used for the first 200 respondents. Secondly, after obtaining the data, conditional logit models were estimated and the results used to update the design. This updated design was then used for the remaining respondents. In both phases each respondent was presented with four choice sets presented in a randomized order.

We deliberately avoided asking respondents to make a private monetary contribution to bird conservation, as is usually done in environmental valuation when the aim is to quantify the values of non-market or public goods (Adamowicz et al., 1998). In such studies the cost is one of the attributes to be traded off, meaning the marginal willingness-to-pay can be calculated for each of the attributes (here birds). In this case we had no interest in the willingness-topay for each attribute but were interested in the trade-off between attributes regardless of cost. Also, the most realistic scenario is one in which the Australian Government would invest tax revenue in the conservation of the birds, rather than individuals paying. An experimental design without a cost attribute was consistent with our aim to reveal people's acceptance of conservation actions for the various bird taxa rather than their willingness-to-pay for these actions. Adding a cost attribute would probably have shifted the choice behaviour away from people's ethical and emotional reactions to proposed conservation actions towards considerations of cost (Carlsson et al., 2007; Pedersen et al., 2011).

The choice experiment was followed by questions about the respondents' demographic background, their attitudes towards and knowledge about birds and their understanding of climate change and its causes (Supplementary Material 2). A four-point rating scale was used where appropriate but avoided the use of 'no opinion', to eliminate social acceptability bias (Garland, 1991) and force deeper psychological engagement with the question (Smyth et al., 2006).

\section{Sampling and data}

Data were collected through a commissioned online survey during September-October 2014. The study was approved by the Charles Darwin University Human Research Ethics Committee (H13115). The sample was recruited from an online panel recruited by MyOpinions PermissionCorp. MyOpinions has an active panel of c. 300,000 verified respondents and has developed, and continues to maintain, an actively managed panel that adheres to a strict researchonly policy governed by industry bodies such as the 
European Society for Opinion and Marketing Research, the Australian Market \& Social Research Society and the Association of Market and Social Research Organisations. MyOpinions is also accredited to ISO 20252 and ISO 26362 professional standards and guidelines. Approximately half of the panel has been recruited from offline sources. MyOpinions offered an incentive of AUD 2 for completion of the survey.

A random sample of adults ( $>18$ years) was drawn from the panel in three Australian states (Tasmania, Victoria, Queensland), aligning with the distribution of the focal species. A total of 7,816 people were sampled and invited to take the survey. When invited, panel members did not know the topic of the survey. We received 1,421 responses (response rate: $18.2 \%)$, of which $302(21.3 \%)$ were incomplete. In total there were 1,119 completions.

\section{Econometric approach}

For the analysis we used a random utility model (McFadden, 1974) as point of departure. Assuming that the researcher does not possess complete information regarding individual decision maker $n$, individual preferences are the sum of a systematic $(V)$ and a random $(\varepsilon)$ component:

$$
U_{n i}=V_{n i}\left(x_{n i} \beta\right)+\varepsilon_{n i}
$$

where $U_{n i}$ is the true but unobservable utility associated with alternative $i$ out of a set of available alternatives $j, V_{n i}$ is the deterministic part that is a function of the attributes $\left(x_{n i}\right), \beta$ is a vector of coefficients reflecting the desirability of the attributes, and $\varepsilon_{n i}$ is unknown and treated as random. Selection of one alternative over another implies that the utility $\left(U_{n i}\right)$ of that alternative is greater than the utility of the other alternatives:

$$
P(i)=\operatorname{Prob}\left(V_{i}+\varepsilon_{i}>V_{j}+\varepsilon_{j}\right) \quad \forall j \in C, j \neq i
$$

Assuming that the error components are distributed independently and identically following a type 1 extreme value distribution, one gets the conditional logit. In this model the probability of individual $n$ choosing alternative $i$ is

$$
P_{n i}=\frac{\exp \left(\mu V_{n i}\right)}{\sum_{j \in C} \exp \left(\mu^{\prime} V_{n j}\right)}
$$

The scale parameter $\mu$ is normalized to 1 as it cannot be identified separately from the vector of parameters in a single data set. One of the shortcomings of the conditional logit is that it erroneously assumes that all respondents have identical preferences. Thus, we additionally used a latent class approach to identify a number of a priori unknown subgroups that may exist in a population (Swait, 2007); each of the subgroups is characterized by a distinct preference structure. Every individual is assumed to belong probabilistically to one of the subgroups. The probability of a respondent choosing alternative $i$, conditional on belonging to a given segment $s$, in the latent class framework is

$$
P_{(n i \mid s)}=\frac{\exp \left(\beta_{s} X_{i n}\right)}{\sum_{j=1}^{J} \exp \left(\beta_{s} X_{j n}\right)}
$$

Application of the latent class model requires external determination of the number of classes separate from the maximization procedure. Thus, we sequentially estimated models with an increasing number of segments $S(S=1,2$, 3, 4...). We used the Bayesian information criteria to select the number of classes (Greene \& Hensher, 2003). All models were estimated using Latent Gold Choice 5.o (Vermunt \& Magidson, 2014).

We conducted likelihood-ratio tests to investigate the relative impact of attributes (Lancsar et al., 2007), as the parameter values cannot be interpreted directly in non-linear models and are confounded with scale. For the latent class model we ran this test separately for each class (Supplementary Material 3).

\section{Results}

The most parsimonious classification of respondent preferences for either actions or bird taxa identified three classes using latent class analysis of the choice modelling results (Table 1). These were characterized as 'Wild preferred' for people who consistently favoured the option of helping species remain where they currently occur over other options, 'No extinction' for people who demonstrated little preference for any action provided taxa did not go extinct, and 'Status quo' for people who were most likely to agree that taxa be left to cope with climate change without intervention of conservation managers. Although classes were statistically indistinguishable in terms of income (AUD 44,700 per annum), education ( $80 \%$ had completed secondary school), gender, and knowledge of birds, respondents in the 'Status quo' class (21\%) were older, and less likely to attribute human agency in climate change or to agree that decisions about adaptation should be made by experts. They were also less likely to enjoy seeing new birds and more likely not to take any notice of them. Two thirds of this class chose the status quo in all four of the choice sets they were offered and the remainder chose it twice (18\%) or three times (17\%). Reasons for a lack of support for adaptation support were split relatively evenly among a belief that climate will have no effect $(29 \%)$, meaning that no adaptation investment would be needed, disapproval of conservation investment generally (27\%), feeling that they did not know enough (22\%), and a belief that money would not be spent appropriately (18\%). The other two classes differed only in their attitude to the adaptation actions proposed, with one class (29\% of respondents) 
favouring protection in the wild ('Wild preferred') more strongly than the other (50\%; 'No extinction').

Although the basis of the latent class analysis was to discover which classes supported conservation, particularly of wild birds, preferences were not immediately evident from direct questions about which actions they found acceptable. More than $65 \%$ of respondents in all classes agreed or strongly agreed that all three options (retention in the wild, assisted colonization, and captivity) were acceptable (Fig. 3). However, $>60 \%$ of respondents varied in the extent of their preferences for a conservation approach (Fig. 4b), with the 'Status quo' respondents less likely to express a preference than the others (breadth of preferences measured as standard deviation across four values for three variables; $\chi^{2}=33.33, \mathrm{P}<0.001$ ). We calculated the difference between proportion of people listing one of the three options as less acceptable than the other two and the proportion listing the same option as more acceptable than the others, and found the contrast was markedly in favour of investment in the wild and against the other options (Fig. 5b).

Although 'Status quo' respondents were less likely to consider expenditure on any of the birds acceptable (Fig. 3), $>86 \%$ of all respondents assigned the same level of importance for all bird taxa (Fig. 4a) and the preferences of the $6 \%$ who favoured one taxon above the others almost cancelled out the preferences of the $4 \%$ who gave a lower importance to one taxon than all the others (Fig. 5a). However, the choice model analysis revealed that respondents in the 'Wild preferred' class also favoured assisted colonization of the rufous scrub-bird should the climate change.

Respondents from Tasmania $(n=249)$, the place to which scrub-birds or mainland brown thornbills would be moved if required, were as likely to be in any of the classes as people from the mainland states (Supplementary Material 4, Fig. S1). More Tasmanian respondents preferred decision making by local communities (30\% compared to $24 \%$ on the mainland) than by the general public (10\% vs $14 \%)$ but the same proportion (6o\%) of Tasmanian respondents and those on the mainland believed conservation managers should make the decision (Supplementary Material 4, Fig. S1).

\section{Discussion}

Four points emerge from our data. Firstly, there was a high level of desire to avoid extinctions across all respondents $(79 \%)$. This proportion is comparable to Europe and the USA: in Europe $93 \%$ of respondents thought that the decline and loss of animal and plant species was 'very serious' (59\%) or 'fairly serious' (14\%; European Union, 2013); in the USA a mean of $66 \%$ of respondents (range 61-78\%) worried 'a great deal' or 'a fair amount' about the extinction of plant and animal species in annual surveys conducted during 2000-2015 (Jones \& Saad, 2015). That our figure (79\%) is higher than the 63\% of Australians willing to pay into a fund to prevent the extinction of threatened species (Zander et al., 2014) was expected, as it was assumed that the government would allocate taxes rather than payments coming directly from the respondents, which is the situation with most threatened species conservation in Australia. It follows that there remains strong support for legislation and policy that prevents the extinction of species, despite the simultaneous promulgation of legislation and policies that undermine democratic principles by permitting developments that lead to extinction (Ellis, 2010).

Secondly, nearly $30 \%$ of respondents expressed a strong preference for maintaining species where they currently occur in the wild. However, these respondents did not rule out moving taxa, such as the rufous scrub-bird, should that prove to be essential. Most respondents were relatively comfortable with options such as assisted colonization or retaining species in a zoo in perpetuity, which many scientists have until recently considered taboo (Hagerman \& Satterfield, 2014), even if these were not actively favoured. This is in contrast to the findings of Hancock \& Gallagher (2014) for a sample of 53 Australian conservation professionals, of whom $21 \%$ felt that, in the foreseeable future, plants should not be moved to places where they are likely to have occurred before anthropogenic change, let alone to sites beyond their former range. Circa $89 \%$ of this group also felt that increased action in situ was the most urgent activity. The strength of opinion among those favouring wild conservation suggests that this option needs to be investigated thoroughly before other options are adopted, but that the more contentious ideas should not be rejected as being unacceptable to the general public, whatever private views are held by conservation professionals.

The low level of support for retaining birds in zoos in perpetuity suggests that this option would need the strongest justification before being adopted. These results resemble those of conservation biologists (Hagerman et al., 2010) and self-selected panels (Tam \& McDaniels, 2013) in Canada and the USA, both of which favoured strategies with low risk but provided qualified support for other options. The relatively small 'Status quo' class expressed too few preferences on actions to influence the debate. Overall the level of climate scepticism ( $17 \%$ believed climate change was a scam or only natural change) was within the range reported from Australia-wide surveys (15-19\%; Greenhill et al., 2014) but in the 'Status quo' class (33\%) it was much closer to that of recent surveys in the USA (35\%; Yale Project on Climate Change Communication, 2014).

Thirdly, although various authors have insisted on the importance of local ownership of the governance processes of assisted colonization (e.g. Hewitt et al., 2011), with the 53 Australian conservation professionals sampled by Hancock 
TABLE 1 Characteristics of three respondent classes identified through latent class analysis of choices made by Australians about strategies that could be used to help bird taxa threatened by climate change. Means sharing the same superscript and those without are not significantly different from each other (Tukey's HSD, $\mathrm{P}<0.05$ )

\begin{tabular}{|c|c|c|c|c|c|}
\hline Characteristic & All & Status quo & Wild preferred & No extinctions & Statistics \\
\hline No. of respondents & 1,119 & 240 & 345 & 534 & \\
\hline Mean income (AUD) & $44,700 \pm$ SD 31,800 & $44,700 \pm$ SD 31,300 & $44,000 \pm$ SD 29,700 & $44,200 \pm$ SD 33,300 & $F=0.14, \mathrm{P}=0.871$ \\
\hline Female (\%) & 50 & 47 & 54 & 49 & $\chi^{2}=3.98, P=0.137$ \\
\hline $\begin{array}{l}\text { Post-secondary education } \\
(\%)\end{array}$ & 66 & 67 & 68 & 65 & $F=0.26, \mathrm{P}=0.773$ \\
\hline Age (years) & $49 \pm$ SD 16 & $52 \pm \operatorname{SD~} 15^{\mathrm{a}}$ & $49 \pm \operatorname{SD~} 16^{\mathrm{b}}$ & $48 \pm \operatorname{SD~} 16^{\mathrm{b}}$ & $F=6.24, \mathrm{P}=0.002$ \\
\hline \multicolumn{6}{|l|}{ Cause of climate change } \\
\hline Human & 31 & $16^{\mathrm{a}}$ & $38^{\mathrm{b}}$ & $34^{\mathrm{b}}$ & \multirow{4}{*}{$\begin{array}{l}\chi^{2}=74.88 \\
P=0.001\end{array}$} \\
\hline Natural + Human & 52 & 51 & 52 & 52 & \\
\hline Natural & 12 & $21^{\mathrm{a}}$ & $7^{\mathrm{b}}$ & $11^{\mathrm{b}}$ & \\
\hline Scam & 5 & 12 & 3 & 4 & \\
\hline \multicolumn{6}{|c|}{ Primary locus of decision making authority } \\
\hline Local people & $25^{\circ}$ & 39 & 20 & 23 & \multirow{3}{*}{$\begin{array}{l}\chi^{2}=74.69 \\
P<0.001\end{array}$} \\
\hline General public & 15 & $28^{\mathrm{a}}$ & $11^{\mathrm{b}}$ & $11^{\mathrm{b}}$ & \\
\hline Conservation scientist & 60 & $33^{\mathrm{a}}$ & $68^{\mathrm{b}}$ & $66^{\mathrm{b}}$ & \\
\hline \multicolumn{6}{|c|}{ Self-reported ability to identify birds } \\
\hline Few & 31 & 35 & 27 & 32 & \multirow{3}{*}{$\begin{array}{l}\chi^{2}=10.91 \\
P=0.091\end{array}$} \\
\hline Common & 62 & 58 & 68 & 60 & \\
\hline Most/All & 7 & 7 & 5 & 8 & \\
\hline \multicolumn{6}{|c|}{ Reaction to encountering a bird species for the first time } \\
\hline Take no notice & 19 & $30^{\mathrm{a}}$ & $16^{\mathrm{b}}$ & $16^{\mathrm{b}}$ & \multirow{3}{*}{$\begin{array}{l}\chi^{2}=26.13 \\
\mathrm{P}<0.001\end{array}$} \\
\hline Enjoy & 66 & $54^{\mathrm{a}}$ & $69^{\mathrm{b}}$ & $69^{\mathrm{b}}$ & \\
\hline Identify/list & 16 & 17 & 14 & 16 & \\
\hline
\end{tabular}

\& Gallagher (2014) believing that 'full approval from all stakeholders at the source and recipient sites' was the most important influence on successful assisted colonization of flora, in the case examined here, respondents demonstrated a high level of trust in conservation professionals. Over $60 \%$ of the respondents were satisfied that conservation professionals had the major say in the decision about the adaptation option most suitable for conserving a species in the face of climate change. That a higher proportion of Tasmanian respondents preferred that decisions about adaptation approaches be made by local communities rather than the general public may reflect an anti-mainland sentiment among those who did not want conservation professionals to make the decision. However, the proportion of Tasmanian respondents willing to accept the direction of experts on appropriate adaptation strategies did not differ from the mainland. This result may reflect ignorance or lack of interest, especially while the question remains hypothetical, but does behove conservation professionals to act in the best interest of the taxa being conserved and recognize that this may be influenced by their own value system.

Fourthly, none of the classes expressed preferences for the particular bird taxa, even though they were informed that two were species and two were subspecies. Studies of a range of taxa have shown that the threat of extinction is the most powerful driver of how people value species, regardless of charisma or other confounding factors, such as distinctiveness (Tisdell, 2014). In this case charisma was avoided as much as possible by confining the choice to four small brown birds. Also, as noted, genetic distinctiveness was deliberately not emphasized, even though the rufous scrub-bird has twice the genetic distinctiveness of the scrubtit and five times that of the brown thornbill as a species (Garnett et al., 2015). Subspecies of brown thornbill, of which there are five, are even less distinct. However, we were as careful as possible not to change respondents' level of understanding by our questions as they would then not have been typical of the wider population. Thus, the lack of preference for species over subspecies, or for the scrub-bird over the others, suggests that prioritization based on genetic distinctiveness, which has been favoured by some scientists and economists (Faith, 1992, 2002; Garnett, 1992; Weitzman, 1998; Joseph et al., 2009), is either not well understood by the general public or is understood but does not affect their preferences. The acceptance of top-down direction on management of bird conservation in the face of climate change could suggest that the public is happy for their views about genetic distinctiveness in setting priorities to be overridden by conservation managers. However, the legislation of most countries, including Australia, gives equal value to all levels of genetic distinctiveness (Garnett \& Christidis, 2007). In Australia, even a taxon such as the Norfolk Island owl Ninox novaeseelandiae undulata, of which the last female was mated with a New Zealand male to retain 
(a) Wild preferred
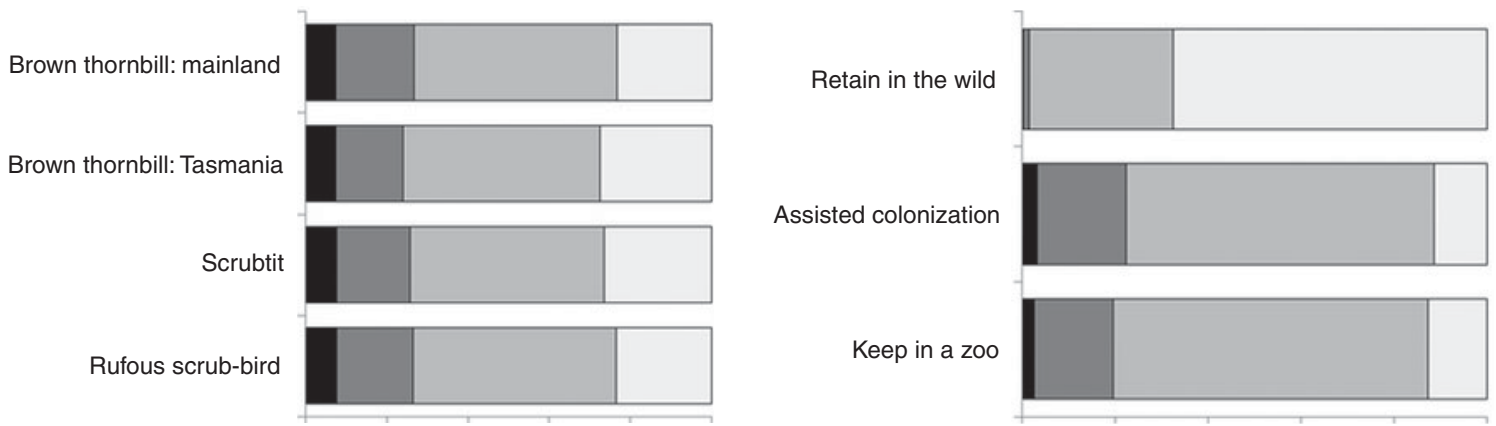

(b) No extinction

Brown thornbill: mainland

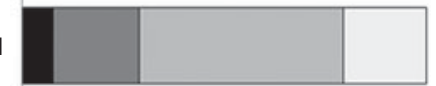

Retain in the wild

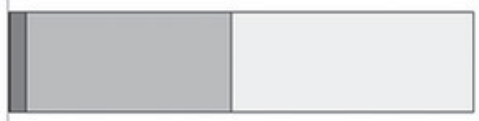

Brown thornbill: Tasmania

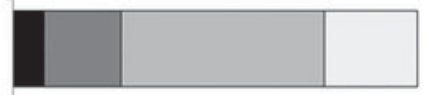

Scrubtit

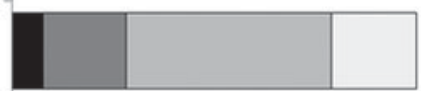

Assisted colonization

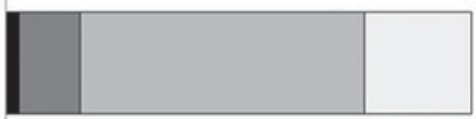

Rufous scrub-bird
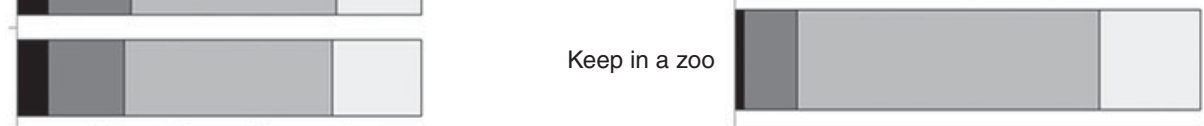

(c) Status quo

Brown thornbill: mainland

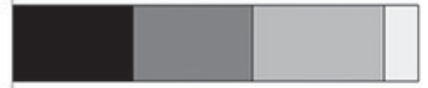

Brown thornbill: Tasmania

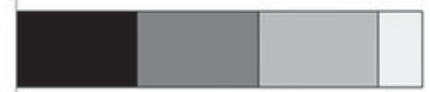

Retain in the wild

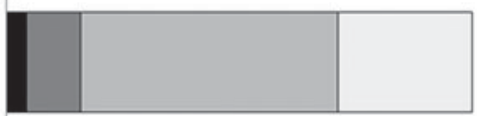

Assisted colonization

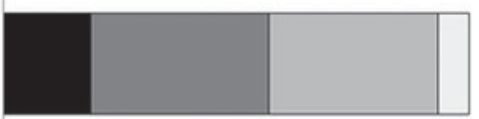

Scrubtit

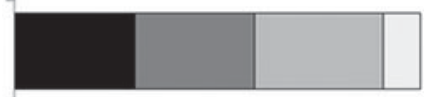

Rufous scrub-bird

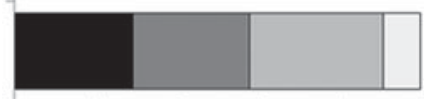

Keep in a zoo

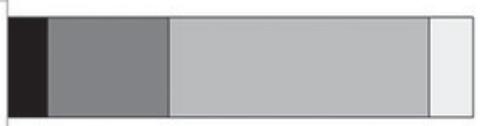

(d) All respondents
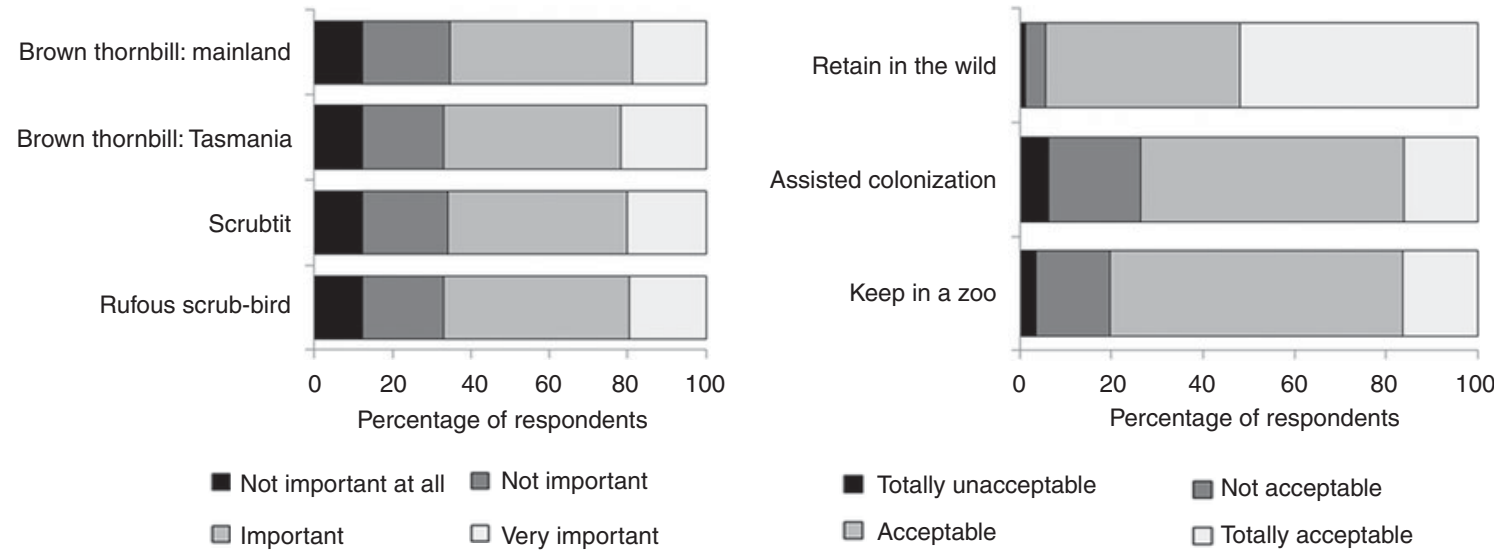

Totally unacceptable

$\square$ Not acceptable

$\square$ Acceptable

$\square$ Totally acceptable

FIG. 3 Stated importance of government investment in conservation of four Australian bird taxa threatened by climate change (left column) and acceptability of three types of conservation approaches (right column) for three respondent classes (a-c) and all respondents $(\mathrm{d})$. 
(a) Type of bird

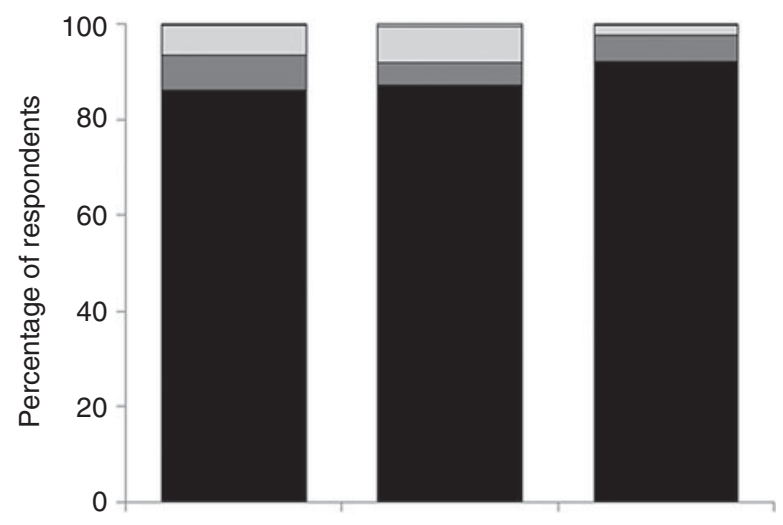

(b) Conservation approach

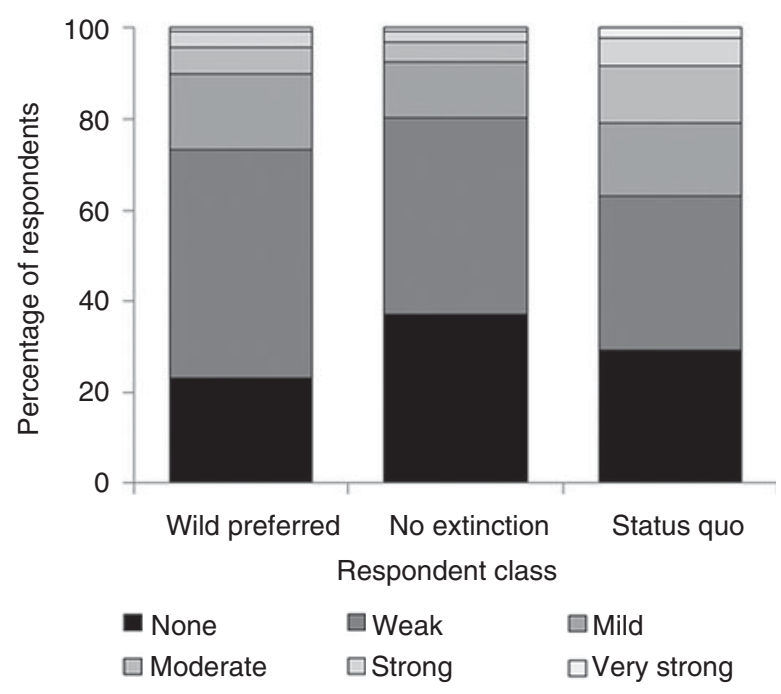

FIG. 4 Extent of variation in preferences (none to very strong) across types of birds (a) and conservation approaches (b).

its genetic potential (Garnett et al., 2011), is given the highest priority in the Australian Government's latest policy documents (Australian Government, 2015). Also, Tasmania has explicitly given equal priority to species and subspecies (Tasmanian Government, 2010). Our results corroborate the approach taken in Tasmania. Whatever the private views of conservation professionals, there is currently no legitimacy in using genetic distinctiveness to prioritize taxa for conservation action in Australia.

Overall, the results suggest that $80 \%$ of the Australian public wishes to avoid extinction, preferably by helping climate-stressed populations to adapt where they currently occur. However, people are relatively sanguine about other approaches if deemed necessary, and are willing to follow the advice of experts, and for them to proceed with climate change adaptation, with appropriate caution as conditions change. We conclude that the public generally supports the more strongly expressed views of conservation advocates (a) Type of bird

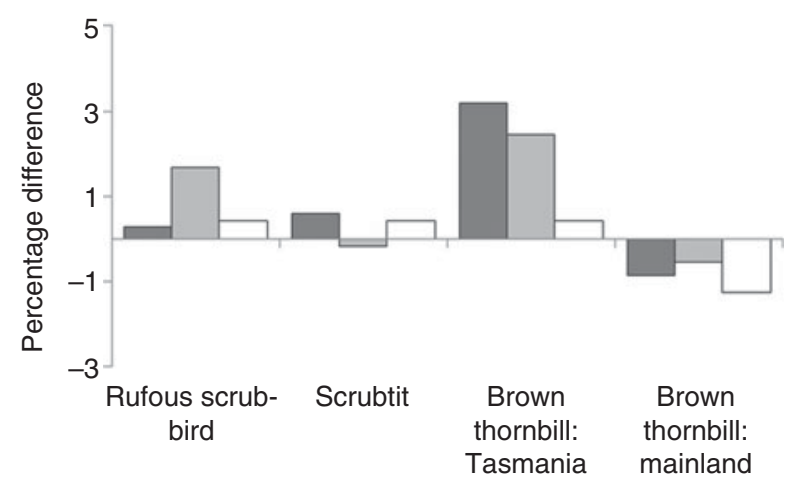

(b) Conservation approach

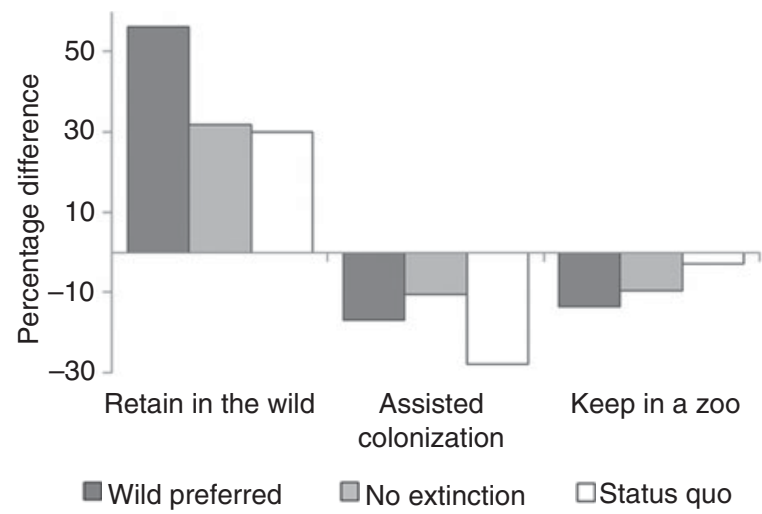

FIG. 5 Percentage difference between those with a clear preference for a bird (a) or conservation approach (b) and those who expressed clear disapproval. Note difference in scale of y-axes.

that the highest priority should be to support existing wild populations (Lundhede et al., 2014), even in the face of climate stress on those populations, but there is acceptance that more drastic interventions may eventually be needed.

\section{Acknowledgements}

The research was funded by an internal faculty grant (Faculty of Engineering, Health, Science and Environment at Charles Darwin University) and is a contribution to the social research undertaken under the auspices of the National Environment Science Programme Threatened Species hub of the Department of the Environment. We thank Julie Ballweg for her early contributions to the design of the research. Graeme Chapman and Allan Richardson kindly allowed their photographs to be used for the survey.

\section{Author contributions}

STG and KKZ conceived the research and initiated the collaboration with SH, TAS and JM. STG, KKZ and JM 
designed the survey, including the choice experiment. JM and KKZ analysed the data. STG, with contributions from $\mathrm{SH}$ and TAS, developed the first draft of the article. All authors contributed to reviewing and finalizing the article and addressing the reviewers' comments.

\section{References}

Adamowicz, W., Boxall, P., Williams, M. \& Louviere, J. (1998) Stated preference approaches for measuring passive use values: choice experiments and contingent valuation. American Journal of Agricultural Economics, 8o, 64-75.

Adger, W.N., Barnett, J., Brown, K., Marshall, N. \& O’Brien, K. (2013) Cultural dimensions of climate change impacts and adaptation. Nature Climate Change, 3, 112-117.

Alroy, J. (2015) Limits to captive breeding of mammals in zoos. Conservation Biology, 29, 926-931.

Araki, H., Cooper, B. \& Blouin, M.S. (2007) Genetic effects of captive breeding cause a rapid, cumulative fitness decline in the wild. Science, 318, 100-103.

Australian Government (2015) Threatened species strategy. Http://www.environment.gov.au/biodiversity/threatened/ publications/threatened-species-strategy [accessed 13 May 2016].

Brambilla, M., Gustin, M. \& Celada, C. (2013) Species appeal predicts conservation status. Biological Conservation, 160, 209-213.

Burbidge, A.A., Byrne, M., Coates, D., Garnett, S.T., Harris, S., Hayward, M.W. et al. (2011) Is Australia ready for assisted colonization? Policy changes required to facilitate translocations under climate change. Pacific Conservation Biology, 17, 259-269.

Carlsson, F., Frykblom, P. \& Lagerkvist, C.J. (2007) Preferences with and without prices-does the price attribute affect behavior in stated preference surveys? Environmental and Resource Economics, $38,155-164$.

Ceccarelli, L. (2011) Manufactured scientific controversy: science, rhetoric, and public debate. Rhetoric \& Public Affairs, 14, 195-228.

Ellis, E. (2010) Extinction and democracy. Http://www.diss.fu-berlin. de/docs/servlets/MCRFileNodeServlet/FUDOCS_derivate_ ooooooo01327/Ellis-The_Extinction_Crisis_and_Democratic_ Theory-110.pdf [accessed 13 May 2016].

European Union (2013) Attitudes Towards Biodiversity. Http://ec. europa.eu/public_opinion/flash/fl_379_en.pdf [accessed 13 May 2016].

Faith, D.P. (1992) Conservation evaluation and phylogenetic diversity. Biological Conservation, 61, 1-10.

Faith, D.P. (2002) Quantifying biodiversity: a phylogenetic perspective. Conservation Biology, 16, 248-252.

GARLAND, R. (1991) The mid-point on a rating scale: is it desirable? Marketing Bulletin, 2, 66-70.

Garnett, S.T. (1992) The Action Plan for Australian Birds. Australian National Parks and Wildlife Service, Canberra, Australia.

GARnETT, S.T. \& Christidis, L. (2007) Implications of changing species definitions for conservation purposes. Bird Conservation International, 17, 187-195.

Garnett, S.T., Olsen, P., Butchart, S.H.M. \& Hoffmann, A.A. (2011) Did hybridization save the Norfolk Island boobook owl Ninox novaeseelandiae undulata? Oryx, 45, 500-504.

Garnett, S.T., Pavey, C.R., Ehmke, G., VanDerWal, J., Hodgson, L. \& FrankLIN, D.C. (2014) Adaptation profiles for Australian birds that are both highly sensitive and highly exposed. In Climate Change
Adaptation Plan for Australian Birds (eds S.T. Garnett, \& D.C. Franklin), pp. 81-250. CSIRO, Melbourne, Australia.

Garnett, S.T., Duursma, D.E., Ehmke, G., Guay, P.-J., Stewart, A., SzA во, J.K. et al. (2015) Biological, ecological, conservation and legal information for all species and subspecies of Australian bird. Scientific Data, 2, 1590061, Https://doi.org/10.1038/sdata.2015.61.

Gómez, J.M., González-Megías, A., Lorite, J., Abdelaziz, M. \& Perfectti, F. (2015) The silent extinction: climate change and the potential hybridization-mediated extinction of endemic highmountain plants. Biodiversity and Conservation, 24, 1843-1857.

Greene, W.H. \& Hensher, D.A. (2003) A latent class model for discrete choice analysis: contrasts with mixed logit. Transportation Research Part B: Methodological, 37, 681-698.

Greenhill, M., Leviston, Z., Leonard, R. \& Walker, I. (2014) Assessing climate change beliefs: response effects of question wording and response alternatives. Public Understanding of Science, 23, $947-965$.

Hagerman, S., Dowlatabadi, H., Satterfield, T. \& McDaniels, T. (2010) Expert views on biodiversity conservation in an era of climate change. Global Environmental Change, 20, 192-207.

Hagerman, S.M. \& Satterfield, T. (2014) Agreed but not preferred: expert views on taboo options for biodiversity conservation, given climate change. Ecological Applications, 24, 548-559.

Hamilton, J.A. \& Miller, J.M. (2016) Adaptive introgression as a resource for management and genetic conservation in a changing climate. Conservation Biology, 30, 33-41.

Hancock, N. \& Gallagher, R. (2014) How ready are we to move species threatened from climate change? Insights into the assisted colonization debate from Australia. Austral Ecology, 39, $830-838$.

Hensher, D.A., Rose, J.M. \& Greene, W.H. (2015) Applied Choice Analysis. Cambridge University Press, Cambridge, UK.

Hewitt, N., Klenk, N., Smith, A.L., Bazely, D.R., Yan, N., Wood, S. et al. (2011) Taking stock of the assisted migration debate. Biological Conservation, 144, 2560-2572.

Jones, J. \& SAAD, L. (2015) Gallup Poll Social Series: Environment. Http://www.gallup.com/file/poll/182111/150325EnviroWorries.pdf [accessed 13 May 2016].

Joseph, L.N., Maloney, R.F. \& Possingham, H.P. (2009) Optimal allocation of resources among threatened species: a project prioritization protocol. Conservation Biology, 23, 328-338.

KLENK, N.L. \& LARSON, B.M.H. (2013) A rhetorical analysis of the scientific debate over assisted colonization. Environmental Science \& Policy, 33, 9-18.

Lancsar, E., Louviere, J. \& Flynn, T. (2007) Several methods to investigate relative attribute impact in stated preference experiments. Social Science and Medicine, 64, 1738-1753.

Lundhede, T.H., Jacobsen, J.B., Hanley, N., FJelds ̊, J., Rahbek, C., Strange, N. \& Thorsen, B.J. (2014) Public support for conserving bird species runs counter to climate change impacts on their distributions. PLoS ONE, 9(7), e101281.

McFadden, D. (1974) Conditional logit analysis of qualitative choice behaviour. In Frontiers in Econometrics (ed. P. Zarembka), pp. 105142. Academic Press, New York, USA.

Pedersen, L.B., KJÆr, T., Kragstrup, J. \& Gyrd-Hansen, D. (2011) Does the inclusion of a cost attribute in forced and unforced choices matter? Results from a web survey applying the discrete choice experiment. Journal of Choice Modelling, 4, 88-109.

Resasco, J., Haddad, N.M., Orrock, J.L., Shoemaker, D., BRUdVig, L.A., DamsChen, E.I. et al. (2014) Landscape corridors can increase invasion by an exotic species and reduce diversity of native species. Ecology, 95, 2033-2039. 
Ricciardi, A. \& Simberloff, D. (2009) Assisted colonization is not a viable conservation strategy. Trends in Ecology \& Evolution, 24, 248-253.

Rose, J.M. \& Bliemer, M.C.J. (2014) Stated choice experimental design theory: the who, the what and the why. In Handbook of Choice Modelling (eds S. Hess \& A. Daly), pp. 152-177. Edward Elgar, Cheltenham, UK.

Smyth, J.D., Dillman, D.A., Christian, L.M. \& Stern, M.J. (2006) Comparing check-all and forced-choice question formats in web surveys. Public Opinion Quarterly, 70, 66-77.

Swait, J. (2007) Advanced choice models. In Valuing Environmental Amenities Using Stated Choice Studies (ed. B.J. Kanninen), pp. 229293. Springer, Heidelberg, Germany.

TAM, J. \& MCDAniels, T.L. (2013) Understanding individual risk perceptions and preferences for climate change adaptations in biological conservation. Environmental Science \& Policy, 27, 114-123.

Tasmanian Government (2010) Prioritisation of Threatened Flora and Fauna Recovery Actions for the Tasmanian NRM Regions. Http://dpipwe.tas.gov.au/Documents/Tasmanian\%2oThreatened\% 2o Species\%2oPrioritisation\%20June\%202010.pdf [accessed 13 May 2016].

Tisdell, C.A. (2014) Human Values and Biodiversity Conservation: The Survival of Wild Species. Edward Elgar, Cheltenham, UK.

Vermunt, J.K. \& Magidson, J. (2014) Upgrade Manual for Latent GOLD Choice 5.o: Basic, Advanced, and Syntax. Statistical Innovations Inc., Belmont, USA.
Weitzman, M.L. (1998) The Noah's Ark problem. Econometrica, 66, 1279-1298.

West, J.M., Julius, S.H., Kareiva, P., Enquist, C., Lawler, J.J., Petersen, B. \& Shaw, M.R. (2009) US natural resources and climate change: concepts and approaches for management adaptation. Environmental Management, 44, 1001-1021.

Yale Project on Climate Change Communication (2014) Estimated \% of adults who think global warming is happening, 2014. Http://environment.yale.edu/poe/v2014 [accessed 13 May 2016].

Zander, K.K., Ainsworth, G.B., Meyerhoff, J. \& Garnett, S.T. (2014) Threatened bird valuation in Australia. PLoS ONE, 9(6), e100411.

\section{Biographical sketches}

STEPHEN GARNETT studies relationships between conservation and livelihoods. KERSTIN $Z_{A N D E R}$ is an environmental economist whose main research interest is the socio-economic and environmental dimensions of human adaptation to climate change and natural hazards. SHANNON HAGERMAN conducts research on evolving conservation mandates and policy, and is currently studying values-based aspects of novel and contested conservation interventions. TERRE SATTERFIELD studies the social science of conservation. JURGEN Meyerhoff is an economist with extensive experience in applying stated preference methods. 